\title{
Penicillin Resistance in Nasopharyngeal Streptococcus pneumoniae among Children with Sickle Cell Disease Immunized with 7-Valent Pneumococcal Conjugate Vaccine
}

\author{
Patricia Belintani Blum Fonseca ${ }^{1}$, Calil Kairalla Farhat ${ }^{1}$, Regina Célia de Menezes Succi ${ }^{1}$, \\ Antônia Maria de Oliveira Machado², Josefina Aparecida Pellegrini Braga ${ }^{1}$
}

${ }^{1}$ Pediatric Department, Universidade Federal de São Paulo, São Paulo, Brazil; ${ }^{2}$ Department of Infectious Disease, Universidade Federal de São Paulo, São Paulo, Brazil.

Email: patricia_blum@uol.com.br

Received March 12 ${ }^{\text {th }}, 2013$; revised April 13 ${ }^{\text {th }}, 2013$; accepted April 21 ${ }^{\text {st }}, 2013$

Copyright (C) 2013 Patricia Belintani Blum Fonseca et al. This is an open access article distributed under the Creative Commons Attribution License, which permits unrestricted use, distribution, and reproduction in any medium, provided the original work is properly cited.

\begin{abstract}
To assess the prevalence, the antimicrobials resistance and to identify risk factors of nasopharyngeal colonization by Streptococcus pneumoniae in children with sickle cell disease (SCD) using prophylactic penicillin and immunized with 7 -valent pneumococcal conjugate vaccine. A total of 424 swabs were collected from the nasopharynx in 216 children with SCD and 109 samples from the control group, both from 2 to 60 months age range. Isolation and identification of pneumococci followed standard procedures. Minimum inhibitory concentration (MIC) for penicillin was determined by the E-test method. Prevalence of nasopharyngeal colonization by pneumococci in children with SCD was 17\%, and $11 \%$ in the control group. The risk factors for increased colonization in children with SCD were the presence of more than five people at home, daycare/school attendance and low prophylaxis compliance. The prevalence of strains with penicillin resistance was $57.5 \%$ in patients with SCD and $25 \%$ in the control group. Conclusions: Prevalence of pneumococci nasopharyngeal colonization was similar among the study groups. Prophylactic use of penicillin may have increased the prevalence of resistant strains. The vaccine did not decrease the colonization with penicillin resistant strains.
\end{abstract}

Keywords: Sickle Cell Disease; Nasopharyngeal Carriage; Streptococcus pneumoniae; Antimicrobial Resistance; Vaccine

\section{Introduction}

Children with sickle cell disease (SCD) have increased susceptibility to infections caused by Streptococcus pneumoniae, due to splenic ischemia that runs chronically and determines the hypofunction of this organ, since the first months of life [1]. The prophylaxis with penicillinsignificantly reduces the risk of serious infection by Streptococcus pneumoniae in children under five years old with SCD; one of the mechanisms involved was the reduction of the colonization of the nasopharynx [2].

The immunization with pneumococcal vaccines is an important tool in protecting these children. The 7-valent pneumococcal conjugate vaccine (PCV 7) was provided free of charge in Brazil by the Ministry of Health since
2002, but only in special situations, including children under five years old with SCD [3]. In Brazil, this vaccine protects against $63 \%$ of the serotypes of $S$. pneumoniae isolated [4].

The 23-valent pneumococcal polysaccharide vaccine does not affect nasopharyngeal colonization [5,6], differing from the PCV 7, which decreases the colonization by the vaccine serotypes $[7,8]$.

Despite the prophylactic use of penicillin and vaccines, pneumococcal infection remains an important cause of morbidity and mortality in these children $[9,10]$. Another major problem is that penicillin prophylaxis may select penicillin-resistant bacteria $[11,12]$.

Today, studies indicate that after the introduction of PCV 7, there was a decrease in the incidence of invasive pneumococcal disease, as well as a change in the antim- 
icrobial resistance profile $[13,14]$, reason why it is essential to monitor invasive and colonizing strains.

In this study, the prevalence, the antimicrobials resistance and the risk factors for carriage of Streptococcus pneumoniae among children with SCD were evaluated using prophylactic penicillin and immunized with PCV 7.

\section{Methods}

The cross-sectional epidemiological study was conducted from November 2007 to November 2008 in the Pediatric Hematology Division of the Federal University of São Paulo (UNIFESP) and approved by its Research Ethics Committee. The parents or legal guardians of the involved patients, received information and clarification about the purpose and possible risks of the study, and in accordance they signed an informed consent form.

The study population consisted of patients with SCD (sickle cell anemia-HbSS; hemoglobinopathy SC-HbSC; or S-beta thalassemia- $-\mathrm{HbS} \beta^{+}, \mathrm{HbS} \beta^{0}$ ), aged between 3 and 60 months and who have attended to at least one consult at the UNIFESP Pediatric Hematology clinic during the period of the study.

All eligible patients were taking prophylaxis for at least one month. Benzathine penicillin 50,000 UI/kg I.M., every 21 days or penicillin $\mathrm{V} \mathrm{50,000} \mathrm{UI/kg/day,} \mathrm{oral,}$ every 12 hours were used for prophylaxis. As both drugs are effective for preventing pneumococcal infection in sickle cell disease, the treatment option was based on the preference of parents or guardians. All eligible patients also were immunized with PCV 7 according to the age. Patients who did not receive prophylaxis despite medical advice and those allergic to penicillin taking erythromycin did not participate in the study.

In all routine visits, the parents or legal guardians of the patients with SCD were interviewed to obtain data regarding:

- Child: age, sex, race, SCD genotype (HbSS, HbSC, $\mathrm{HbS} \beta$ ), frequency in day care centers or schools, and living conditions.

- Prophylaxis: age of onset of prophylaxis, type of medication, and compliance. The report by the parents of delay of benzathine penicillin for a period longer than five days or not daily use of penicillin $\mathrm{V}$ (whether occurring in general or just prior to the material collecting) was considered irregular compliance.

- Vaccination: the status in relation to PCV 7 was confirmed by the patient's vaccination card. A child was considered as age appropriately vaccinated if at the time of sampling had received all recommended doses, according to the age: three doses in the first year of life (two, four and six months) and a booster dose between 12 to 15 months of age, two doses for children who started immunization between seven and eleven months of age, with a booster at 15 months, and two doses for children under five years who started immunization after 12 months of age. Those with fewer doses than recommended by age were defined as partially vaccinated.

The control group consisted by children from 2 to 60 months of age, both sexes, all races and who were under monitoring at the Pediatric Hematology clinic of UNIFESP, with diagnosis of other hematological diseases which do not determine increased risk for pneumococcal infection, taking no antimicrobial prophylaxis or any antimicrobials at the time of collecting and had not received the PCV 7.

Children with SCD underwent nasopharyngeal samples collections in all routine visits during the period of the study, with a minimum interval of 30 days, while patients in the control group underwent only one collection throughout the study.

The samples were collected with a small flexible swab (Transwab plain medium, Medical Wire \& Equipment Co, England). After the collecting, the swab was immersed directly in the transport medium (Amies-Medical Wire \& Equipment Co, England), and sent within 1 - 3 hours, at ambient temperature, to the Bacteriology Laboratory of UNIFESP, where the material was inoculated on $5 \%$ sheep blood agar plates. The plates were then incubated at $35^{\circ} \mathrm{C} \pm 1{ }^{\circ} \mathrm{C}$ with $\mathrm{CO}_{2}$ tension of $5 \%$ to $10 \%$ in atmosphere produced by candle jar for 24 to 48 hours. The presence of a gray-green zone around the colonies ( $\alpha$-hemolysis) was presumptive of Streptococcus pneumoniae. Confirmation of the agent was performed by optochin susceptibility and bile solubility assays. Isolates were frozen and stored at $-70^{\circ} \mathrm{C}$.

Assessment of antimicrobial resistance was performed and interpreted according to the recommendations of the Clinical and Laboratory Standards Institute (CLSI), 2008 [15]. Penicillin susceptibility was assessed by the oxacillin disc diffusion method $(1 \mu \mathrm{g})$, with an inhibition zone $\geq 20 \mathrm{~mm}$ considered indicative of susceptibility to penicillin, and a halo $\leq 19 \mathrm{~mm}$, as resistance to penicillin [15]. To confirm the strains resistant to penicillin was determined the minimum inhibitory concentration (MIC) for penicillin by the E-test, only in pneumococcal strains resistant to oxacillin (halo $\leq 19 \mathrm{~mm}$ ).

The MIC for penicillin was interpreted according to CLSI recommendations, 2008 [15], taking into account that the strains were obtained from the nasopharynx (colonizing strains) and the antimicrobial agent was oral penicillin $\mathrm{V}$, as: sensitive $\leq 0.06 \mu \mathrm{g} / \mathrm{mL}$; intermediate $=$ 0.12 to $1 \mu \mathrm{g} / \mathrm{mL}$; and resistant $\geq 2.0 \mu \mathrm{g} / \mathrm{mL}$. For ceftriaxone MIC was considered: sensitive $\leq 1 \mu \mathrm{g} / \mathrm{mL}$; intermediate $=2 \mu \mathrm{g} / \mathrm{mL}$; and resistant $\geq 4 \mu \mathrm{g} / \mathrm{mL}$ [15]. Bacte- 
rial resistance was also tested for: erythromycin, cotrimoxazole, levofloxacin and vancomycin.

For categorical variables analysis were applied: chisquare test with Yates correction or Fisher's exact test. The evaluation of risk factors for pneumococcal infection in children with sickle cell disease was made considering the patient as a sampling unit and after univariate analysis. To test the importance of risk factors with p-value $<$ 0.10 we applied the logistic regression technique with the stepwise method of variable selection. Descriptive level (p) $<0.05$ or $5 \%$ was considered statistically significant, rejecting the hypothesis of equality.

\section{Results}

The study enrolled 216 of the 221 patients with SCD in the elected age group attended during the time of selection. Five patients were excluded, two of them due to penicillin allergic reaction and three for not agreeing with the use of prophylaxis. The age of the patients ranged from 3 to 60 months old, mean and standard deviation of $25.8 \pm 17.8$ months and median of 22.5 months. The control group comprised 109 children, aged 2 to 60 months old, mean and standard deviation of $29 \pm 18.8$ months and median of 30 months.

Pneumococci was isolated from the nasopharynx of 37 among the 216 children with SCD (colonization $=17 \%$ ) and from 12 of the 109 control patients (colonization = $11 \%)$.

More than one sample was obtained from 138 of 216 children with SCD (64\%), totalizing 424 samples. 40 of 424 samples $(9.4 \%)$ were positive for pneumococci, with three patients showing two positive samples. For this study 533 nasopharyns samples were collected (Table 1).

There was no difference between the rate of nasopharyngeal colonization by Streptococcus pneumoniae among patients with SCD 37/216 (17.1\%) and the control group $12 / 109(11 \%)(\mathrm{p}=0.196)$.

The evaluation of risk factors for colonization among children with SCD is demonstrated in Table 2. The risk factors were: irregular prophylaxis use, participation in day care centers or schools and more than five people living at home.

Thirty one of the 40 strains isolated $(77.5 \%)$ in the SCD group and five of the 12 strains isolated (41.7\%) in the control group exhibited resistance to screening with oxacillin discs. The results of the MIC evaluation confirmed that 23 of the $40(57.5 \%)$ strains tested in the SCD group and three of the twelve (25\%) strains isolated in the control group really exhibited penicillin resistance. Pneumococcal profile resistance to penicillin and others antibiotics tested is given in Table 3.

The proportion of nasopharyngeal colonization by penicillin-resistant pneumococci was higher in children
Table 1. Frequency and number of samples obtained from the nasopharynx of children with sickle cell disease and the control group.

\begin{tabular}{ccc}
\hline $\begin{array}{c}\text { Frequency of samples } \\
\text { collection }\end{array}$ & SCD $(\mathbf{n}=\mathbf{2 1 6})$ & Controls (n= 109) \\
\hline 1 & $78(36 \%)$ & $109(100 \%)$ \\
2 & $82(38 \%)$ & \\
3 & $43(20 \%)$ & \\
4 & $12(5.5 \%)$ & \\
5 & $1(0.5 \%)$ & 109 \\
Total of samples (533) & 424 & \\
\hline $\mathrm{n}=$ number of patients with sickle cell disease and controls.
\end{tabular}

with SCD 21/216 (9.7\%) than in controls 3/109 (2.8\%) (p $=0.04$ ).

It was found that $66.7 \%$ of patients with SCD in regular use of penicillin prophylaxis were colonized by penicillin-resistant strains $(p=0.03)$ and that the PCV 7 did not interfere in the isolation of resistant strains $(p=1.0)$ (Table 4).

\section{Discussion}

In 1984, Anglin et al.[16] published the first study evaluating the effect of penicillin prophylaxis on nasopharyngeal colonization, and found a prevalence of $11.1 \%$ in patients with sickle cell anemia and $37.1 \%$ in control group without prophylaxis. Other authors found colonization rates among children with SCD taking penicillin ranging from $8 \%$ to $15.5 \%$ [11,17,18]. In the Brazilian study published in 2005 , we found similar results, with a colonization rate of $13.3 \%$ [6]. In none of these studies, patients received the PCV 7 .

Alexander et al. [19] assessed the nasopharyngeal carriage rate of pneumococci in children with SCD before and after the introduction of PCV 7, founding a colonization rate of $21 \%$ and $9 \%$ respectively. We found in this study a different result, $11 \%$ of colonization rate in the control group and $17 \%$ in the SCD group. Suggesting, as in other studies, that the rate of colonization did not change after introduction of PVC 7 by replacement of the serotypes not presented in the vaccine $[11,20]$.

It was expected that the control group without prophylaxis and vaccination would present higher colonization, but this has not been observed. This prevalence may have been underestimated, because children in the control group underwent a single evaluation only; moreover, among children with SCD was a higher prevalence of penicillin-resistant strains, despite prophylaxis.

More than five residents at home and attending day care or schools were in our study greater risk factors for colonization, showing that the contact favors the spread of pneumococci [21]. 
Table 2. Analysis of risk factors for nasopharyngeal colonization by Streptococcus pneumoniae of 216 children with sickle cell disease.

\begin{tabular}{|c|c|c|c|c|c|}
\hline \multicolumn{2}{|c|}{ Risk factor n (\%) } & \multirow{2}{*}{$\begin{array}{c}\text { Colonized }(\mathbf{n}=\mathbf{3 7}) \\
18(16.8 \%)\end{array}$} & \multirow{2}{*}{$\begin{array}{c}\text { No colonized }(\mathbf{n}=\mathbf{1 7 9}) \\
89(83.2 \%)\end{array}$} & \multirow{3}{*}{$\begin{array}{c}\mathbf{p}^{*} \\
0.905\end{array}$} & \multirow[t]{3}{*}{ Multivariate Analysis $^{* *}$} \\
\hline \multirow{2}{*}{ Age group (months) } & $\leq 24(\mathrm{n}=107)$ & & & & \\
\hline & $>24(\mathrm{n}=109)$ & $19(17.4 \%)$ & $90(82.6 \%)$ & & \\
\hline \multirow{2}{*}{ Gender } & Female $(\mathrm{n}=116)$ & $19(16.4 \%)$ & $97(83.6 \%)$ & \multirow{2}{*}{0.752} & \\
\hline & Male $(\mathrm{n}=100)$ & $18(18.0 \%)$ & $82(82.0 \%)$ & & \\
\hline \multirow{2}{*}{ Race } & White $(\mathrm{n}=57)$ & $11(19.3 \%)$ & $46(80.7 \%)$ & \multirow{2}{*}{0.612} & \\
\hline & No white $(\mathrm{n}=159)$ & $26(16.4 \%)$ & $133(83.6 \%)$ & & \\
\hline \multirow{2}{*}{ Genotype } & $\mathrm{Hb} \mathrm{SC} / \mathrm{S} \beta+(\mathrm{n}=97)$ & $22(22.7 \%)$ & $75(77.3 \%)$ & \multirow{2}{*}{0.050} & \\
\hline & $\mathrm{Hb} \mathrm{SS} / \mathrm{S} \beta 0(\mathrm{n}=119)$ & $15(12.6 \%)$ & $104(87.4 \%)$ & & \\
\hline \multirow{2}{*}{ Prophilaxis } & Pen benzatin $(n=120)$ & $18(15.0 \%)$ & $102(85.0 \%)$ & \multirow{2}{*}{0.353} & \\
\hline & Penicillin V $(\mathrm{n}=96)$ & $19(19.8 \%)$ & $77(80.2 \%)$ & & \\
\hline \multirow{2}{*}{ Prophilaxis Compliance } & Irregular $(\mathrm{n}=27)$ & $9(33.3 \%)$ & $18(66.7 \%)$ & \multirow{2}{*}{0.027} & $\mathrm{p}=0.007$ \\
\hline & Regular $(\mathrm{n}=189)$ & $28(14.8 \%)$ & $161(85.2 \%)$ & & $3.72[1.42 ; 9.71]$ \\
\hline \multirow{2}{*}{7 -valent vaccine for age } & Complete $(\mathrm{n}=158)$ & $26(16.5 \%)$ & $132(83.5 \%)$ & \multirow{2}{*}{0.664} & \\
\hline & Incomplete $(\mathrm{n}=58)$ & $11(19.0 \%)$ & $47(81.0 \%)$ & & \\
\hline \multirow{2}{*}{ Day care center/school } & No $(n=162)$ & $21(13.0 \%)$ & $141(87.0 \%)$ & \multirow{2}{*}{0.004} & $\mathrm{P}=0.003$ \\
\hline & Yes $(n=54)$ & $16(29.6 \%)$ & $38(70.4 \%)$ & & $3.28[1.49 ; 7.20]$ \\
\hline \multirow{2}{*}{$\begin{array}{l}\text { Children under } 5 \text { years at } \\
\text { home }\end{array}$} & No $(n=172)$ & $29(16.9 \%)$ & $143(83.1 \%)$ & \multirow{2}{*}{0.835} & \\
\hline & Yes $(n=44)$ & $8(18.2 \%)$ & $36(81.8 \%)$ & & \\
\hline \multirow{2}{*}{$\begin{array}{c}\text { More than } 5 \text { residents at } \\
\text { home }\end{array}$} & No $(n=162)$ & $21(13.0 \%)$ & $141(87.0 \%)$ & \multirow{2}{*}{0.004} & $\mathrm{p}=0.004$ \\
\hline & Yes $(\mathrm{n}=54)$ & $16(29.6 \%)$ & $38(70.4 \%)$ & & $3.14[1.44 ; 6.88]$ \\
\hline
\end{tabular}

$\mathrm{p}^{*}=$ Univariate analysis; ${ }^{* *}$ Logistic regression by stepwise method and odds ratio with $95 \%$ confidence interval.

Table 3. Resistance profile of 52 strains of Streptococcus pneumoniae isolated from the nasopharynx of patients with sickle cell disease and the controls.

\begin{tabular}{ccc}
\hline ANTIBIOTIC & $\begin{array}{c}\text { Patients samples } \\
(\mathbf{n}=\mathbf{4 0})\end{array}$ & $\begin{array}{c}\text { Controls samples } \\
(\mathbf{n}=\mathbf{1 2})\end{array}$ \\
\hline Penicillin & 23 & 3 \\
R intermediate & $21(52.5 \%)$ & $3(25 \%)$ \\
R elevated & $2(5 \%)$ & 0 \\
Ceftriaxone & $6(15 \%)$ & $2(16.7 \%)$ \\
Erythromycin & $6(15 \%)$ & $1(8.3 \%)$ \\
Cotrimoxazole & $26(65 \%)$ & $6(50 \%)$ \\
Levofloxacin & 0 & 0 \\
Vancomycin & 0 & 0 \\
\hline $\mathrm{R}=$ resistance. & &
\end{tabular}

Some studies suggest that the age of the child interferes with the prevalence of colonization by Streptococcus pneumoniae, with more colonization among children under two years [22,23]. Evaluating children with SCD, some authors have also obtained the same result $[6,17]$, but in this study, the age of 24 months was not a risk factor for nasopharyngeal colonization.

Patients with $\mathrm{HbSC}$ and $\mathrm{HbS}^{+}$should demonstrate better preserved splenic function in the first five years of
Table 4. Resistance of Streptococcus pneumoniae isolated from the nasopharynx of patients with SCD according to prophilaxis compliance and vaccination status.

\begin{tabular}{ccccc}
\hline & & $\begin{array}{c}\text { Pen S } \\
(\mathbf{n}=17)\end{array}$ & $\begin{array}{c}\text { Pen I/R } \\
(\mathbf{n}=23)\end{array}$ & $\mathbf{p}^{*}$ \\
\hline $\begin{array}{c}\text { Prophilaxis } \\
\text { Compliance }\end{array}$ & Regular $(\mathrm{n}=33)$ & $11(33.3 \%)$ & $22(66.7 \%)$ & 0.03 \\
$\begin{array}{c}\text { 7-valent } \\
\text { vaccine for } \\
\text { age }\end{array}$ & Complete $(\mathrm{n}=30)$ & $13(43.3 \%)$ & $17(56.7 \%)$ & 1.0 \\
\hline
\end{tabular}

$\mathrm{p}^{*}=$ Fisher's exact test; Pen $=$ penicillin; $\mathrm{S}=$ sensitive; $\mathrm{I}=$ intermediate resistance; $\mathrm{R}=$ resistant.

life than patients with $\mathrm{HbSS}$ and $\mathrm{HbS} \beta$, determining a better immune response, and therefore, lower risk of invasive pneumococcal disease [24]. Verifying if colonization rate could also be different according to genotypes, we found no difference in the multivariate analysis, which was also observed in previous studies $[6,17]$.

Comparing the influence of the type of prophylaxis on colonization, we found no statistical difference, similarly to what we observed previously [6], suggesting that benzathine penicillin seems to be as effective as penicillin $\mathrm{V}$ in reducing pneumococcal colonization.

Analyzing the influence of adherence to antimicrobial 
prophylaxis on the prevalence of colonization, we found that irregular adherence to prophylaxis increased 3.7 times the child susceptibility to colonization, which was expected, once the period without medication would increase the chances of colonization, since prophylaxis reduces it $[2,11,16]$.

We observed an increase of pneumococcal penicillinresistant strains in children with SCD (57.5\%) compared to the control group (25\%), similarly to other studies [16, 17]. From 2002 to 2003, we observed in children with SCD using prophylactic penicillin and not immunized with the PCV 7 , that only $21.4 \%$ of the strains showed resistance [6], indicating that in five years the isolation of resistant strains had a significant increase, despite the introduction of PCV 7.

As immunization with PCV 7 decreases the colonization by the vaccine serotypes [7,8], these patients could be colonized by non-vaccine serotypes and with a high prevalence of penicillin resistance caused by the impact of the prophylaxis.

We found that the regular use of prophylactic penicillin in patients with SCD may be related to increased colonization by penicillin-resistant strains.

All these data suggest that the prophylactic use of penicillin can collaborate to increase the colonization by resistant strains to this antimicrobial. Thus, in the future, a change in the pneumococcal prophylaxis might be necessary for these patients, although further studies evaluating the resistance of invasive strains are essential in this matter.

In 2011, McCavit et al.[10] published a retrospective analyze of invasive Streptococcus pneumoniae infections in children with SCD since pneumococcal conjugate vaccine licensure and seen a recent increase in the frequency of invasive pneumococcal disease which is caused by non-vaccine serotypes. Ten cases were reported and one isolated strains $(10 \%)$ was penicillin intermediate resistant, the others strains were sensitive. However, it is worth remembering that the breakpoints of resistance to penicillin are different for colonizing and invasive strains [15].

We observed no difference regarding ceftriaxone in resistance between patients and the control group, but there was an increased resistance compared with our previous study, which showed none ceftriaxone-resistant strains [6].

In our study, $85 \%$ of isolated pneumococcal strains were sensitive to erythromycin, however, it's noteworthy that pneumococcal resistance to macrolides is increasing worldwide [25-27], and erythromycin appears to be a good option for pneumococcal prophylaxis in children with SCD, although is currently used only for those allergic to penicillin.
The monitoring invasive strains in children with SCD immunized with pneumococcal conjugate vaccines are essential for an epidemiological perspective and for comparison with current surveillance data of colonizing strains. Only with these data, we can assess whether the use of penicillin or ceftriaxone in the febrile episodes of these patients remains appropriate. It's also important to conduct further studies to assess the minimum time required for prophylaxis after the introduction of PVC 7.

Due to the ease process of obtaining samples and the possibility of representing at least a part of invasive disease profile, monitoring the pneumococcal resistance profile through samples obtained from the nasopharynx of children with SCD must be constantly made.

We concluded that the prophylactic use of penicillin may have increased the prevalence of resistant strains. The vaccine did not decrease the colonization with penicillin resistant strains.

\section{Acknowledgements}

We thank the children and their parents for the participation. We also acknowledge the staff of the Bacteriology Laboratory of Universidade Federal de São Paulo for isolation of pneumococci.

\section{REFERENCES}

[1] H. A. Pearson, "Sickle Cell Anemia and Serious Infections Due to Encapsulated Bacteria," Journal of Infectious Disease, Vol. 136, Suppl. 1, 1977, pp. S25-S30. doi:10.1093/infdis/136.Supplement.S25

[2] M. H. Gaston, J. I. Verter, G. Woods, C. Pegelow, J. Kelleher, G. Presbury, H. Zarkowsky, E. Vichinsky, R. Iyer, et al., "Prophylaxis with Oral Penicillin in Children with Sickle Cell Anemia: A Randomized Trial," New England Journal of Medicine, Vol. 314, No. 25, 1986, pp. 15931599. doi:10.1056/NEJM198606193142501

[3] M. da Saúde do Brasil, "Manual dos Centros de Referência para Imunobiológicos Especiais. Organizado pela Coordenação de Imunizações e Auto-Suficiência em Imunobiológicos," Ministério da Saúde, Secretaria de Vigilância à Saúde, Programa Nacional de Imunização 2005, Brasília, 2006, $150 \mathrm{p}$.

[4] M. C. C. Brandileone, A. L. S. Andrade, J. L. Di Fabio, M. L. L. S. Guerra and R. Austrian, "Appropriateness of a Pneumococcal Conjugate Vaccine in Brazil: Potential Impact of Age and Clinical Diagnosis, with Emphasis on Meningitis," Journal of Infectious Disease, Vol. 187, No. 8, 2003, pp.1206-1212. doi:10.1086/374396

[5] G. D. Overturf, R. Field, C. Lam, S. Lee and D. R. Powars, "Nasopharyngeal Carriage of Pneumococci in Children with Sickle Cell Disease," Infection and Immunity, Vol. 28, No. 3, 1980, pp. 1048-1050.

[6] P. B. Fonseca, J. A. Braga, A. M. Machado, M. C. C. Brandileone and C. K. Farhat, "Colonização Nasofaríngea 
pelo Streptococcus pneumoniae em Crianças com Doença Falciforme Usando Penicilina Profilática," Jornal de Pediatria, Vol. 81, No. 2, 2005, pp. 149-154. doi:10.1590/S0021-75572005000300011

[7] F. Ghaffar, T. Barton, J. Lozano, L. S. Muniz, P. Hicks, V. Gan, N. Ahmad and G. H. McCracken Jr., "Effect of 7Valent Pneumococcal Conjugate Vaccine on Nasopharyngeal Colonization by Streptococcus pneumonia in the First 2 Years of Life," Clinical Infectious Diseases, Vol. 39, No. 7, 2004, pp. 930-938. doi:10.1086/423379

[8] V. F. Jones, C. Harrison, G. G. Stout and J Hopkins, "Nasopharyngeal Colonization with Heptavalent Pneumococcal Conjugate Vaccine Serotypes of Streptococcus pneumonia with Prolonged Vaccine Dosing Intervals," Pediatric Infectious Diseases Journal, Vol. 24, No. 11, 2005, pp. 969-973. doi:10.1097/01.inf.0000187030.83080.8a

[9] C. Booth, B. Inusa and S. K. Obaro, "Infection in Sickle Cell Disease: A Review," International Journal of Infectious Diseases, Vol. 14, No. 1, 2010, pp. e2-e12. doi:10.1016/j.ijid.2009.03.010

[10] T. M. McCavit, C. T. Quinn, C. Techasaensiri and Z. R. Rogers, "Increase in Invasive Streptococcus pneumoniae Infections in Children with Sickle Cell Disease Since Pneumococcal Conjugate Vaccine Licensure," The Journal of Pediatrics, Vol. 158, No. 3, 2011, pp. 505-507. doi:10.1016/j.jpeds.2010.11.025

[11] V. S. Sakhalkar, A. S. Sarnaik, B. I. Asmar, R. ConnerWarren, W. Shurney and N. M. Abdel-Haq, "Prevalence of Penicillin-Nonsusceptible Streptococcus pneumoniae in Nasopharyngeal Cultures from Patients with Sickle Cell Disease," Southern Medical Journal, Vol. 94, No. 4, 2001, pp. 401-404.

[12] S. J. Schrag, C. Peña, J. Fernández, J. Sánchez, V. Gómez, E. Pérez, J. M. Feris and R. E. Besser, "Effect of ShortCourse, High-Dose Amoxicillin Therapy on Resistant Pneumococcal Carriage: A Randomized Trial," The Journal of the American Medical Association, Vol. 286, No. 1, 2001, pp. 49-56. doi:10.1001/jama.286.1.49

[13] M. H. Kyaw, R. Lynfield, W. Schaffner, A. S. Craig, J. Hadler, A. Reingold, A. R. Thomas, L. H. Harrison, N. M. Bennett, M. M. Farley, R. R.Facklam, J. H. Jorgensen, J. Besser, E. R. Zell, A. Schuchat and C. G. Whitney, "Effect of Introduction of the Pneumococcal Conjugate Vaccine on Drug-Resistant Streptococcus pneumonia," The New England Journal of Medicine, Vol. 354, No. 14, 2006, pp. 1455-1463. doi:10.1056/NEJMoa051642

[14] R. Dagan, "Impact of Pneumococcal Conjugate Vaccine on Infections Caused by Antibiotic-Resistant Streptococcus pneumonia," Clinical Microbiology and Infection, Vol. 3, No. 1, 2009, pp. 16-20. doi:10.1111/j.1469-0691.2009.02726.x

[15] Clinical and Laboratory Standards Institute, "Performance Standards for Antimicrobial Susceptibility Testing," Eighteenth Informational Supplement, CLSI Publication M100S18, Vol. 28, No. 1, 2008.

[16] D. L. Anglin, J. D. Siegel, D. L. Pacini, S. J. Smith, G. Adams and G. R. Buchanan, "Effect of Penicillin Prophylaxis on Nasopharyngeal Colonization with Streptoco- ccus pneumoniae in Children with Sickle Cell Anemia," Journal of Pediatrics, Vol. 104, No. 1, 1984, pp. 18-22. doi:10.1016/S0022-3476(84)80582-X

[17] C. F. Norris, S. R. Mahannah, K. Smith-Witley, K. O. Frempong and K. L. McGowan, "Pneumococcal Colonization in Children with Sickle Cell Disease," Journal of Pediatrics, Vol. 129, No. 6, 1996, pp. 821-827. doi:10.1016/S0022-3476(96)70025-2

[18] G. M. Woods, J. H. Jorgensen, M. A. Waclawiw, C. Reid, W. Wang, C. H. Pegelow, Z. R. Rogers, R. V. Iyer, C. T. Holbrook, T. R. Kinney, E. Vichinsky, M. R. DeBaun, N. J. Grossman, M. D. Thomas and J. M. Falletta, "Influence of Penicillin Prophylaxis on Antimicrobial Resistance in Nasopharyngeal $S$. pneumoniae among Children with Sickle Cell Anemia," Journal of Pediatric Hematology/ Oncology, Vol. 19, No. 4, 1997, pp. 327-333. doi:10.1097/00043426-199707000-00011

[19] E. Alexander, P. Telfer, H. Rashid, K. A. Ali and R. Booy, "Nasopharyngeal Carriage Rate of Streptococcus pneumoniae in Children with Sickle Cell Disease before and after the Introduction of Heptavalent Pneumococcal Conjugate Vaccine," Journal of Infection and Public Health, Vol. 1, No. 1, 2008, pp. 40-44. doi:10.1016/j.jiph.2008.08.005

[20] N. Frazão, R. Sá-Leão and H. Lencastre, "Impact of a Single Dose of the 7-Valent Pneumococcal Conjugate Vaccine on Colonization," Vaccine, Vol. 28, No. 19, 2010, pp. 3445-3452. doi:10.1016/j.vaccine.2010.02.070

[21] L. C. Rey, B. Wolf, L. B. Moreira, J. Verhoef and C. K. Farhat, "S. pneumoniae Isolados da Nasofaringe de Crianças Sadias e com Pneumonia: Taxa de Colonização e Suscetibilidade aos Antimicrobianos," Jornal de Pediatria, Vol. 78, No. 2, 2002, pp. 105-112. doi:10.1590/S0021-75572002000200008

[22] M. G. M. Novales, F. S. Snatos, H. G. Gallardo, B. L. Miranda, G. E. Aviles, M. N. C. Barajas, M. P. Torres and O. M. Hermandez, "Streptococcus pneumoniae: Low Frequency of Penicillin Resistance and High Resistance to Trimetoprim-Sulfamethoxazole in Nasopharyngeal Isolates from Children in a Rural Area in Mexico," Archives of Medical Research, Vol. 28, No. 4, 1997, pp. 559-563.

[23] A. Woolfson, R. Huebner, A. Wasas, M. Chola, P. Godfrey-Faussett and K. Klugman, "Nasopharyngeal Carriage of Community-Acquired-Antibiotic-Resistant Streptococcus pneumoniae in a Gambian Pediatric Population," Bulletin of the World Health Organization, Vol. 75, No. 5, 1997, pp. 453-462.

[24] P. A. Lane, J, L. O’Connel, J. L Lear, Z. R. Rogers, G. M. Woods, K. L. Hassell, D. L. Wethers, D. W. Luckey and G. R. Buchanan, "Functional Asplenia in Hemoglobin SC Disease," Blood, Vol. 85, No. 8, 1995, pp. 2238-2244.

[25] J. Melo-Cristino, M. Ramirez, N. Serrano and T. Hänscheid, "Macrolide Resistance in Streptococcus pneumoniae Isolated from Patients with Community-Acquired Lower Respiratory Tract Infections in Portugal: Results of a 3-Year (1999-2001) Multicenter Surveillance Study," Microbial Drug Resistance, Vol. 9, No. 1, 2003, pp. 73-80. doi:10.1089/107662903764736364

[26] K. Waits and S. Brown, "Antimicrobial Resistance among 
Sickle Cell Disease Immunized with 7-Valent Pneumococcal Conjugate Vaccine

Isolates of Respiratory Tract Infection Pathogens from the Southern United States: Data from the PROTEKT US Surveillance Program 2000/2001," Southern Medical Journal, Vol. 96, No. 10, 2003, pp. 974-985.

doi:10.1097/01.SMJ.0000091066.74656.6C

[27] A. D. Conradi, E. Calbo, E. Cuchí, et al., "Spanish Pneu- mococcal Infection Study Network, Impact of Amoxicillin, Associated or Not with Clavulanic Acid, on Pharyngeal Colonization and Selection of Streptococcus pneumoniae Resistance in Children under 5 Years of Age," European Journal of Pediatrics, Vol. 166, No. 5, 2007, pp. 467-471. doi:10.1007/s00431-006-0270-5 